\title{
High Anxiety Levels and Growth Hormone Secretion in Children with Short Stature
}

\author{
Nitsan Dror, MD, Michal Pantanowitz, PhD, Dan Nemet, MD, MHA and Alon Eliakim, MD* \\ Endocrine Unit, Pediatric Department, Meir Medical Center, Sackler School of Medicine, Israel
}

\begin{abstract}
Growth hormone $(\mathrm{GH})$ provocation test, which includes repeated blood measurements following pharmacological stimuli, may be stressful for the children and their family. Thirty-three short stature children with impaired growth rate were studied during $\mathrm{GH}$ provocation tests to determine if the test is associated with increased anxiety and if increased anxiety affects the test results.

Anxiety of the children and their parents was evaluated before and at the end the GH provocation test using State-Trait Inventory (STAI) questionnaire for the parents and State-Trait Inventory Child (STAIC) questionnaire for the children.

Pre-test, $61 \%$ of the children had moderate anxiety, $27 \%$ high anxiety and $12 \%$ low anxiety scores. Children with high anxiety state had $47 \%$ lower peak GH compared to children with low to moderate anxiety scores. In addition, mean anxiety score was $20 \%$ higher among $\mathrm{GH}$ deficient compared to $\mathrm{GH}$ sufficient participants.

In summary, high anxiety prior to $\mathrm{GH}$ provocation test was associated with lower GH secretion. Whether high anxiety interferes with $\mathrm{GH}$ secretion and leads to low $\mathrm{GH}$ responses is still to be determined.
\end{abstract}

\section{Keywords}

Growth hormone, Anxiety, Provocation tests, Growth hormone deficiency, Secretion

\section{Introduction}

Short stature is a major concern to many families and one of the leading causes for referral to pediatric endocrinology clinics [1]. Since growth hormone $(\mathrm{GH})$ secretion is pulsatile, the diagnosis of $\mathrm{GH}$ deficiency in children is challenging. A single random blood sample for $\mathrm{GH}$ level cannot distinguish between healthy or GH deficient child. Thus, GH provocation tests, which include repeated blood measurements following pharmacological stimuli, have been developed [2]. Two abnormal GH secretion tests are needed in order to diagnose GH deficiency.

$\mathrm{GH}$ provocation tests require medical care setting, overnight fast, and insertion of intravenous line. As a consequence, the test may be stressful for the children and their parents leading to activation of stress mechanisms. The stress systems consists mainly of two axis the Hypothalamic-pituitary-adrenal axis (HPA) mediated through Corticotropin releasing hormone ( $\mathrm{CRH}$ ) and the brain stem locus coeruleus-norepinephrine system regulating the sympathetic nervous system [3]. The central activation by the stress response leads to glucocorticoid (cortisol) and catecholamine (norepinephrine) release that shifts the metabolism toward catabolism [4]. Although the stress system result in adaptive endocrine and metabolic changes, major stress or chronic activation can have adverse effects such as insulin resistance, obesity, immune dysfunction, hypogonadism reduced GH secretion $[4,5]$.

Previously it has been shown that generalized and social anxiety disorders were more common in children with $\mathrm{GH}$ deficiency and $\mathrm{GH}$ treatment may reduce the anxiety in these children [6]. The etiology for anxiety in GH deficiency children is not fully understood, it was suggested that $\mathrm{GH}$ is involved in neurotransmission and neuromodulation in the central nervous system and might have an effect on neural function including mood and cognition [7]. Whether GH provocation test increase anxiety levels during the test and whether anxiety can effect GH secretion has not been studied. Therefore, the aim of the present study was to evaluate the anxiety state of both the child and his/her parents using standard question-

*Corresponding author: Alon Eliakim, MD, Department of Pediatrics, Meir Medical Center, 59 Tchernichovski St, Kfar Saba, 44281, Israel, Tel: 972-9-7472134, Fax: 972-9-7471303

Accepted: February 02, 2021

Published online: February 04, 2021

Citation: Dror N, Pantanowitz M, Nemet D, et al. (2021) High Anxiety Levels and Growth Hormone Secretion in Children with Short Stature. Ann Endocrinol Metab 4(1):50-54 
Citation: Dror N, Pantanowitz M, Nemet D, et al. (2021) High Anxiety Levels and Growth Hormone Secretion in Children with Short Stature. Ann Endocrinol Metab 4(1):50-54

Table 1: Anthropometric characteristics of the study participants.

\begin{tabular}{|l|l|}
\hline & Mean \pm SD \\
\hline Age (years) & $9.8 \pm 3.3$ \\
\hline Girls/Boys & $16 / 17$ \\
\hline Weight $(\mathrm{Kg})$ & $28.2 \pm 11.4$ \\
\hline SDS weight & $-1.4 \pm 1.1$ \\
\hline Height (cm) & $124.0 \pm 16.9$ \\
\hline SDS height & $-2.1 \pm 0.3$ \\
\hline BMI & $17.3 \pm 3.2$ \\
\hline SDS BMI & $-0.2 \pm 1.2$ \\
\hline Tanner stage & $1.2 \pm 0.6$ \\
\hline
\end{tabular}

BMI: Body Mass Index; SDS: Standard Deviations Score

naires, as well as measurements of physiological parameters (i.e. heart rate and blood pressure) and blood catecholamines (i.e. epinephrine, norepinephrine and dopamine), and to use the data collected to assess the effect of anxiety on GH secretion during the provocative test. We hypothesized that children will have high anxiety during the provocation test and high anxiety will attenuate $\mathrm{GH}$ secretion.

\section{Methods}

\section{Participants}

Thirty-three children participated in the study. Anthropometric characteristics of the study participants are summarized in Table 1. Participants were children who were evaluated for short stature and impaired growth rate in the endocrine clinic at the Meir Medical Center, Sackler School of Medicine, Tel-Aviv University and were requested to perform a provocation test for $\mathrm{GH}$ secretion. The study was approved by the Institutional Review Board, and appropriate informed consent was obtained from all the participants and their parents.

\section{Anxiety questionnaires}

Since short stature is a major concern to the whole family, anxiety of the children and their parents was evaluated before and at the end the GH provocation test using State-Trait Inventory (STAI) questionnaire for the parents and State-Trait Inventory Child (STAIC) questionnaire for the children $[8,9]$.

The questionnaires have two components, the first evaluates general anxiety (trait) and the second evaluates the current anxiety (state). Each component consists of a 20-item scale, rating from hardly ever true to often true. A separate score is given for the State scale and to the Trait scale. Scores range from 20 to 80 . The higher scores indicate a greater level of anxiety. Low anxiety trait and state was defined as a score between $20-40$ points. Moderated anxiety trait and state was defined as a score between 40 to 60 points and high anxiety trait and state was defined as a score $>60$ points.

\section{Physiological measures}

The children's heart rate and blood pressure were measured using Welch Allyn Vital Signs Monitor (VSM 300) every
30 minutes throughout their stay in the pediatric endocrine clinic for the $\mathrm{GH}$ provocation test.

\section{GH provocation tests}

Each participant performed a commonly used GH provocation test (i.e. clonidine test or glucagon test). In case of an abnormal GH secretion in the first provocation test, a repeat $\mathrm{GH}$ provocation test was performed using standard protocols. The anxiety was evaluated only in the first GH provocation test.

\section{Blood sampling and analysis}

Tests were performed in the morning, following an overnight fast. However, water was given ad-libitum prior to testing to avoid dehydration. An indwelling venous catheter was inserted 30 min prior to the first blood draw, after allowing subjects to rest and sit quietly. In the clonidine test, blood samples were collected before and 30, 60, 90 and 120 minutes after the beginning of the test. In the glucagon test, blood samples were collected before and 60, 90, 120, 150 and 180 minutes after the beginning of the test. In addition, blood samples for epinephrine, norepinephrine and dopamine were collected before and at $120 \mathrm{~min}$ after the beginning of the test. Blood samples were immediately spun at $3000 \mathrm{rpm}$ and at $4{ }^{\circ} \mathrm{C}$, for $20 \mathrm{~min}$. All serum specimens from each individual for each test were analyzed in the same batch by an experienced technician, who was blinded to the anxiety levels of the participants and to the order of the samples.

Growth hormone: GH serum concentrations were determined by IMMULITE 2000 Siemens Analyzer solid phase, twosite, chemiluminescent immunometric assay using murine mono-clonal anti-GH antibody. Intra-assay CV was 2.9-4.6\%, inter-assay CV was $4.2-6.6 \%$ and the analytical sensitivity was $0.01 \mathrm{ng} / \mathrm{ml}$. Normal values in our laboratory are 0.1-7.5 ng/ $\mathrm{ml}$.

Insulin-like growth factor-I (IGF-I): IGF-I was extracted from IGF-binding proteins (IGFBPs) using the acid-ethanol extraction method. Serum IGF-I was measured using immune-chemi-luminescent assay (ICMA) using the Immulite 2000 Siemens Analyzer, with analytical sensitivity of $25 \mathrm{ng} /$ $\mathrm{ml}$, and intra- and inter-assay coefficient of variation $<8 \%$.

Plasma catecholamines: Plasma catecholamines were analyzed by the Bio-Rad high-precision liquid chromatography (HPLC) (Bio-Rad laboratories Inc., Hercules, CA). Epinephrine Intra-assay CV was 4.2-7.8\%, inter-assay CV was 3.7-7.2\% and the sensitivity was $4 \mathrm{pg} / \mathrm{ml}$. Norepinephrine Intra-assay CV was $2.5-4.2 \%$, inter-assay CV was $1.9-3.7 \%$ and the sensitivity was $10 \mathrm{pg} / \mathrm{ml}$.

Imaging: Head magnetic resonance imaging (MRI) was preformed to all children with GH deficiency.

\section{Statistical analysis}

Two-way repeated measure ANOVA with Bonferroni corrections was used to assess the effect of anxiety on $\mathrm{GH}$ levels with time serving as the within group factor and type of anxiety level as the between group factor. Unpaired t-tests were performed to compare anxiety state scores between $\mathrm{GH}$ defi- 


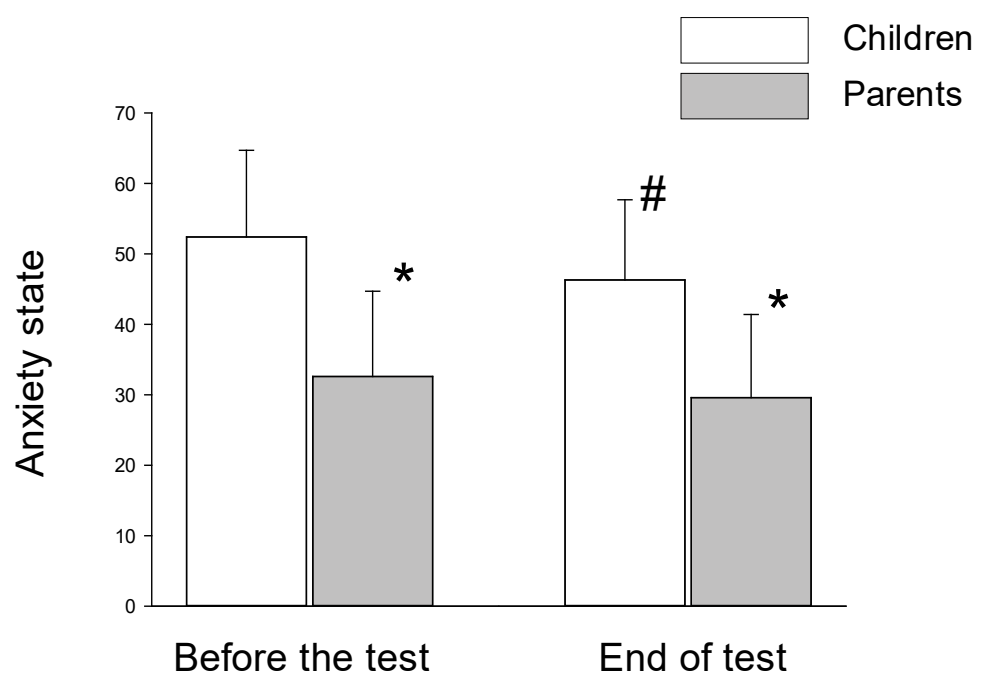

Figure 1: Anxiety state score among children and their parents before and at the end of GH provocation test ( ${ }^{*} p<0.01$ for children versus parents, $" p<0.05$ for children before and at the end of the test).

GH: Growth Hormone

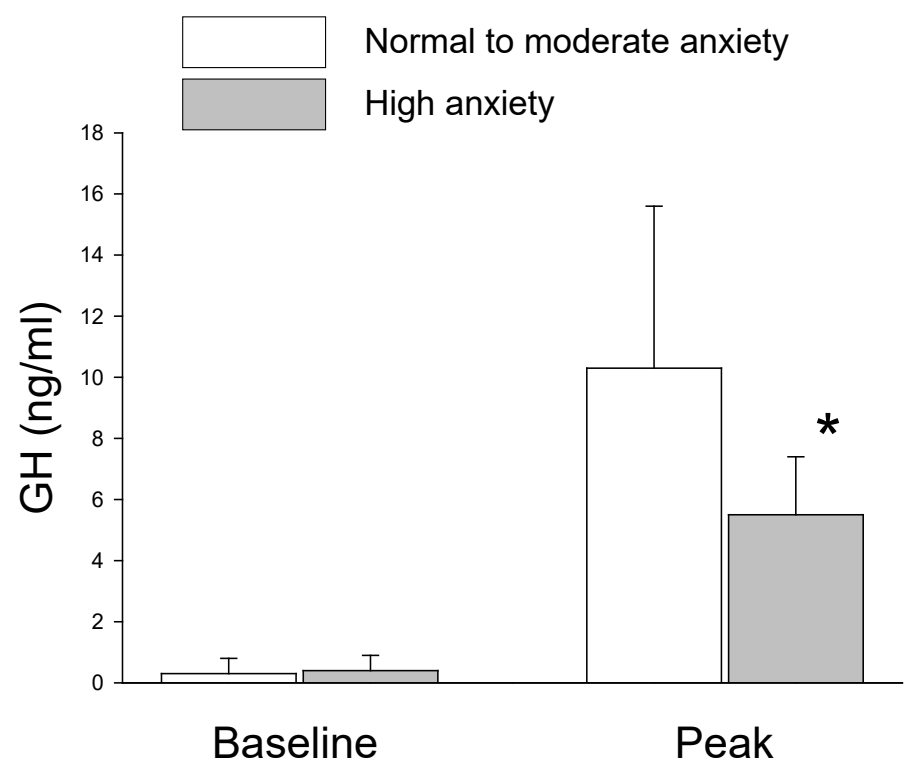

Figure 2: The effect of anxiety state on peak GH secretion among children during GH provocation test ("for high anxiety group versus normal to moderate anxiety group $p<0.01$ ).

GH: Growth Hormone

cient and GH sufficient participants, and to compare peak $\mathrm{GH}$ levels between normal to moderate and high anxiety state participants among the GH sufficient group. Pearson correlations were computed between anxiety state scores and $\mathrm{GH}$ peak levels. Data are presented as mean \pm SD. Significance was set at $\mathrm{p}<0.05$.

\section{Results}

Thirty-three children completed the $\mathrm{GH}$ provocation test and the anxiety questionnaires.

\section{Anxiety questionnaires}

Anxiety trait: The children and their parents had a low anxiety trait scores (32.9 \pm 6.9 and $29.6 \pm 11.8$ respectively). There was no significant difference in the anxiety trait score between the children and parents.

Anxiety state: At the beginning of the test 20 (61\%) children had moderate anxiety state and 9 (27\%) children had high anxiety state. Only $4(12 \%)$ children had low anxiety state. There were no significant age differences between the groups and no correlation was found between the age of the child and the anxiety state. The average anxiety state of the children was reduced by the end of the GH provocation test compared to the beginning but was still in the moderate range $(52.4 \pm 12.3$ vs. $46.3 \pm 11.4$ at the beginning and the end of the test, respectively; $\mathrm{P}=0.02$ ). The parent's had low anxi- 
Citation: Dror N, Pantanowitz M, Nemet D, et al. (2021) High Anxiety Levels and Growth Hormone Secretion in Children with Short Stature. Ann Endocrinol Metab 4(1):50-54

ety state both before and at the end of the test and their anxiety state score was significantly lower than their children's (Figure 1).

\section{Anxiety and growth hormone secretion}

Due to the small number of children with low anxiety state $(n=4)$, and lack of anthropometric and physiological differences, we combined children with low and moderate anxiety to a single group. There were no statistically significant differences in baseline $\mathrm{GH}$ levels between children with low to moderate anxiety and children with high anxiety state. However, children with high anxiety state had significantly lower peak GH secretion during the first provocation test compared to children with low to moderate state of anxiety (Figure 2).

In the high anxiety group, only two children (22\%) had normal GH secretion. The mean anxiety state was significantly higher among $\mathrm{GH}$ deficient participants compared to $\mathrm{GH}$ sufficient participants $(59.6 \pm 16.4$ versus $49.7 \pm 9.4$ points, respectively; $p<0.04)$. There was a significant inverse correlation between anxiety level and peak $\mathrm{GH}$ secretion $(r=-0.3, p$ $<0.05)$.

A second $\mathrm{GH}$ provocation test was performed only if $\mathrm{GH}$ secretion in the first test was low. However, anxiety was evaluated only during the first GH provocation test to avoid learning effect. There were six children (25\%) with low GH secretion in the low to moderate anxiety group and six children $(66 \%)$ in the high anxiety group. In the second provocation test, 4 of the 6 children (66\%) from the low-moderate anxiety group had a second test compatible with GH deficiency ( 3 with severe GH deficiency). In the high anxiety group, 5 of the 6 children (83\%) had a second provocation test compatible with $\mathrm{GH}$ deficiency (one with severe GH deficiency). There were no significant differences in Insulin-like growth factor I (IGF-I) levels between the two anxiety groups (143.7 \pm 72.3 versus $198.3 \pm 121.8 \mathrm{ng} / \mathrm{ml}$ for low to moderate anxiety and high anxiety, respectively). No pituitary abnormality was found in MRI in the children with GH deficiency.

\section{Physiological measures and catecholamine}

Physiological measures (i.e. heart rate and blood pressure) and catecholamine levels during the $\mathrm{GH}$ provocation test are summarized in Table 2.

There was a significant decrease in blood pressure and norepinephrine levels from the beginning to the end of the test. No statistically significant differences in heart rate, blood pressure or catecholamine levels were found between the different groups.

\section{Discussion}

The present study examined the levels of anxiety during $\mathrm{GH}$ provocation test in children with short stature who were evaluated for $\mathrm{GH}$ deficiency, and assessed the effect of anxiety on $\mathrm{GH}$ secretion. The main findings of the study were that the majority of children (88\%) begin the $\mathrm{GH}$ provocation test with moderate to high state of anxiety. This is important since a high anxiety state is associated with higher level of $\mathrm{GH}$ deficiency and may attenuate $\mathrm{GH}$ secretion during the test, leading to a possible false test failure in many of the children.

A major goal in the evaluation of children with short stature is to identify the small fraction of children with pathologic genetic, systemic and endocrine causes. GH deficiency is an important, treatable, endocrine cause for short stature. Due to the pulsatile nature of $\mathrm{GH}$ secretion, the diagnosis of $\mathrm{GH}$ deficiency relies on the $\mathrm{GH}$ response to provocation tests in addition to auxological documentation, and IGF-I measurements. However, provocative GH testing has several limitations since they rely upon $\mathrm{GH}$ assays of variable accuracy and reproducibility. Moreover, most pediatric endocrinologists define a "normal" GH response by a serum GH concentration of $>10 \mathrm{ng} / \mathrm{ml}$, although the most accurate threshold varies with the assay and laboratory used. To overcome some of these limitations, a similar, single monoclonal $\mathrm{GH}$ assay for GH measurement has been used since 2010 nationwide in Israel [10]. As a result, the cut-off level was changed, and a "normal" response is now defined as serum $\mathrm{GH}$ concentration of $>7.5 \mathrm{ng} / \mathrm{ml}$ and severe $\mathrm{GH}$ deficiency as GH levels $<5 \mathrm{ng} /$ $\mathrm{ml}$.

One of the most striking finding of the present study was the level of anxiety associated with the GH provocation test. Eighty-eight percent of the children with short stature who were evaluated for $\mathrm{GH}$ deficiency and were requested to perform $\mathrm{GH}$ provocation test came to the endocrine clinic on the day of the test in a moderate to high anxiety state. Moreover, although somatic measurements decreased from the beginning of the test towards its end, as indicated by the significant decrease in blood pressure and circulating norepinephrine levels, anxiety state scores were still elevated in most of the children at the end of the test. This finding reinforces previous reports relating stress, anxiety and depression with altered levels of hormones [11-14]. The anxiety occurred despite a very thorough explanation to the child and family about the whole examination procedure prior to the $\mathrm{GH}$ provocation test. In addition, since environments changes may affect hormonal responses [15] the test was performed in an environment that was familiar to the participants (the ambulatory day care of the pediatric endocrinology clinic). Moreover, in

Table 2: Physiologic measures (heart rate and blood pressure) and catecholamine levels during the growth hormone provocation tests.

\begin{tabular}{|l|l|l|l|}
\hline & Pre-test (mean \pm SD) & Post-test (mean \pm SD) & P value \\
\hline Heart rate (beat/min) & $88 \pm 16$ & $81 \pm 19$ & 0.09 \\
\hline Blood pressure $(\mathrm{mm} \mathrm{Hg})$ & $99 \pm 9 / 57 \pm 8$ & $92 \pm 11 / 50 \pm 8$ & 0.005 \\
\hline Dopamine $(\mathrm{ng} / \mathrm{ml})$ & $28.8 \pm 10$ & $28.6 \pm 22$ & 0.59 \\
\hline Epinephrine $(\mathrm{pg} / \mathrm{ml})$ & $55.93 \pm 110$ & $37.76 \pm 110$ & 0.39 \\
\hline Norepinephrine $(\mathrm{pg} / \mathrm{ml})$ & $156.96 \pm 93$ & $85.20 \pm 64$ & 0.001 \\
\hline
\end{tabular}


Citation: Dror N, Pantanowitz M, Nemet D, et al. (2021) High Anxiety Levels and Growth Hormone Secretion in Children with Short Stature. Ann Endocrinol Metab 4(1):50-54

real-life setting, in many cases the motivation for evaluation and treatment in children with short stature comes from the parents. However, the children's anxiety throughout the test cannot be related to parental influence due to parental anxiety since anxiety state score of the parents were normal. Finally, the children's anxiety cannot be related also to a general anxiety personality since the children's anxiety trait scores were normal. The results however indicate that pediatric endocrinologists, nurses and other medical care personnel should be aware of the anxiety that accompany GH provocation tests, and efforts should be made to find appropriate approaches to reduce and mitigate that anxiety.

Clinically, the most substantial finding of the present study was that peak $\mathrm{GH}$ secretion was significantly reduced in the children with the high anxiety state. Only two children in the high anxiety group reached the normal cut-off level of $7.5 \mathrm{ng} / \mathrm{ml}$, and GH deficient children had significantly higher anxiety state scores compared to $\mathrm{GH}$ sufficient children. Thus, one may argue that $\mathrm{GH}$ deficiency leads to a higher anxiety state prior to $\mathrm{GH}$ provocation tests [6]. On the other hand, it can be argued that anxiety from the test it self interferes with GH secretion during the test and indeed we found inverse correlation between anxiety state scores and peak $\mathrm{GH}$ levels. Further studies including healthy children may answer this question. It is well established that chronic stress may suppress $\mathrm{GH}$ secretion as seen in psychological dwarfism $[16,17]$, but the acute effect of anxiety on GH secretion is yet unknown. Whether the blunted $\mathrm{GH}$ response is related to acute activation of the sympathetic system and hypothalamic-pituitary-adrenal axis is yet to be determined. However, we did not find correlation between the $\mathrm{GH}$ response to the provocation test and catecholamine levels.

In summary, the present study indicates higher anxiety state in $\mathrm{GH}$ deficient children, but also may suggest that children's anxiety interferes with GH secretion and gives another possible important explanation to the high rate of false low $\mathrm{GH}$ responses in $\mathrm{GH}$ provocative tests. This may ultimately lead in some cases to incorrect diagnosis of $\mathrm{GH}$ deficiency and as a result to unnecessary $\mathrm{GH}$ treatment. The anxiety associated with the $\mathrm{GH}$ provocation test occurred despite a routine and thorough explanation of the procedures and familiarity with the test location and personnel. This mandates development of better anxiety reduction techniques by the medical staff that will decrease the anxiety related to the $\mathrm{GH}$ provocation tests in order to improve test sensitivity and interpretation.

\section{Declaration of Conflicting Interests}

The authors declared no potential conflicts of interest with respect to the research, authorship, and/or publication of this article.

\section{Funding}

This research was supported by a grant from the "Time for action" foundation.

\section{References}

1. Thomsett MJ (2010) The spectrum of clinical paediatric endocrinology: 28 years of referrals to an individual consultant. Journal of Paediatrics and Child Health 46: 304-349.

2. Ranke $M B$ (2011) Diagnostics of endocrine function in children and adolescents. ( $4^{\text {th }}$ edn), Basel: Karger 115-129.

3. Chrousos GP (2009) Stress and disorders of the stress system. Nature Reviews Endocrinology 5: 374-381.

4. Pervanidou P, Chrousos GP (2012) Metabolic consequences of stress during childhood and adolescence. Metabolism 61: 611619.

5. Morris P, Hopwood M, Maguire K, et al. (2004) Blunted growth hormone response to clonidine in post-traumatic stress disorder. Psychoneuro Endocrinology 22: 269-278.

6. Akaltun I, Çayır A, Kara T, et al. (2018) Is growth hormone deficiency associated with anxiety disorder and depressive symptoms in children and adolescents?: A case-control study. Growth Horm IGF Res 41: 23-27.

7. Arámburo C, Alba Betancourt C, Luna M, et al. (2014) Expression and function of growth hormone in the nervous system: A brief review. General and Comparative Endocrinology 203: 35-42.

8. Spielberger CD, Gorsuch RL, Lushene R, et al. (1983) Manual for the state-trait anxiety inventory. Consult Psychol Press Palo Alto.

9. Teichman Y, Melnick H (1984) Hebrew Manual for the STAI, STAIC.

10. Trainer PJ, Barth J, Sturgeon C, et al. (2006) Consensus statement on the standardisation of $\mathrm{GH}$ assays. European Journal of Endocrinology 155: 1-2.

11. Lima Ojeda JM, Rupprecht R, Baghai TC (2018) Neurobiology of depression: A neuro developmental approach. World J Biol Psychiatry 19: 349-359.

12. Faravelli C, Carolina Lo Sauro, Godini L, et al. (2012) Childhood stressful events, HPA axis and anxiety disorders. World J Psychiatry 2: 13-25.

13. Pervanidou P, Chrousos GP (2010) Neuroendocrinology of post-traumatic stress disorder. Prog Brain Res 182: 149-160.

14. Juruena MF, Eror F, Cleare AJ, et al. (2020) The role of early life stress in HPA axis and anxiety. Advances in Experimental Medicine and Biology 1191: 141-153.

15. Herman JP, McKlveen JM, Ghosal S, et al. (2016) Regulation of the hypothalamic-pituitary-adrenocortical stress response. Compr Physiol 6: 603-621.

16. Powell GF, Brasel JA, Raiti S, et al. (1967) Emotional deprivation and growth retardation simulating idiopathic hypopituitarism. II. Endocrinologic evaluation of the syndrome. N Engl J Med 276: 1279-1283.

17. Del Tondo J, Por I, Hu W, et al. (2008) Associations between the human growth hormone-releasing hormone- and neuropeptide-Y-immunoreactive systems in the human diencephalon: A possible morphological substrate of the impact of stress on growth. Neuroscience 153: 1146-1152.

DOI: $10.36959 / 433 / 566$

Copyright: (C) 2021 Dror N, et al. This is an open-access article distributed under the terms of the Creative Commons Attribution License, which permits unrestricted use, distribution, and reproduction in any medium, provided the original author and source are credited. 